\title{
Continuation versus Discontinuation of Oxytocin in Active Phase of Labour- A Randomised Trial
}

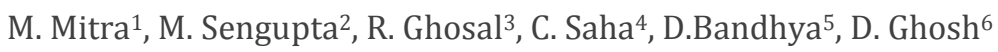

\begin{abstract}
${ }^{1}$ Department of Obstetrics and Gynaecology, Baranagar State General Hospital, Baranagar, West Bengal, India. ${ }^{2}$ Department of Obstetrics and Gynaecology, R. G. Kar Medial College and Hospital, Kolkata, West Bengal, India. ${ }^{3}$ Department of Obstetrics and Gynaecology, R. G. Kar Medial College and Hospital, Kolkata, West Bengal, India. ${ }^{4}$ Department of Obstetrics and Gynaecology, R. G. Kar Medial College and Hospital, Kolkata, West Bengal, India. ${ }^{5}$ Department of Obstetrics and Gynaecology, R. G. Kar Medial College and Hospital, Kolkata, West Bengal, India. ${ }^{6}$ Department of Obstetrics and Gynaecology, R. G. Kar Medial College and Hospital, Kolkata, West Bengal, India.
\end{abstract}

\section{ABSTRACT}

\section{BACKGROUND}

Oxytocin is used in more than $50 \%$ of the deliveries for induction of labour in many delivery units. Currently, there is no consensus whether oxytocin should be continued until delivery or can be discontinued after established active phase of labour. Theoretically, once labour contractions are established, the endogenous production of prostaglandin from the endometrium may be enough to maintain appropriate uterine activity without further stimulation with oxytocin. Our study was formulated to investigate whether discontinuation of oxytocin infusion has any effect on the duration of active phase of labour, mode of delivery, and maternal or neonatal morbidity.

\section{METHODS}

This open-label prospective randomised controlled trial included 200 pregnant women at term with premature rupture of membranes. Primigravidas $>/=18$ years of age with a single viable foetus and cephalic presentation at term with cervical dilation $</=3 \mathrm{~cm}$ on internal examination were included in the study. 100 patients were allocated in each group after simple randomisation. Oxytocin infusion was initiated in both the groups for labour induction at a rate of $3 \mathrm{mIU} / \mathrm{min}$ and incremented by $3 \mathrm{mIU} / \mathrm{min}$ every 30 minutes till cervical dilatation of $5 \mathrm{cms}$ was achieved. At this point, for those women who were allocated in Case group, oxytocin was discontinued. In Control group oxytocin was continued in the same dose until delivery.

\section{RESULTS}

Demographic characteristics of the participants (age, religion, residence, socioeconomic status, education) were similar in both the groups. The mean duration of active phase of labour in women who delivered vaginally $(2.45$ hours in discontinued versus 2.35 hours in continued group) and mean duration of second stage of labour ( 0.96 hours in discontinued versus 0.89 hours in continued) were similar in both the groups. The results of mode of delivery (80\% vaginal delivery in discontinued versus $75 \%$ vaginal delivery in continued), maximum dose of oxytocin used (5.16 $\mathrm{mIU} / \mathrm{min}$ in discontinued versus $5.19 \mathrm{mIU} / \mathrm{min}$ in continued) and postpartum haemorrhage ( $15 \%$ in discontinued versus $18 \%$ in continued) were also similar.

\section{CONCLUSIONS}

Discontinuation of oxytocin in the active stage of labour does not prolong labour and has no adverse maternal or neonatal outcome. Moreover, continuation of oxytocin in active stage of labour has increased incidence of uterine tachysystole and foetal heart rate abnormality. Therefore, it is an alternative and viable option to discontinue oxytocin in the active stage of labour.

\section{KEY WORDS}

Discontinuation of Oxytocin, Active Phase of Labour, Induction of Labour

\author{
Corresponding Author: \\ Dr. Mallika Sengupta, \\ RMO Quarter, Block B, Flat 1, \\ R. G. Kar Medial College and Hospital, \\ 1, Khudiram Bose Sarani, Kolkata-700004, \\ West Bengal, India. \\ E-mail: drmallikasengupta@gmail.com
}

DOI: $10.14260 /$ jemds/2019/725

Financial or Other Competing Interests: None.

How to Cite This Article:

Mitra M, Sengupta M, Ghosal R, et al. Continuation versus discontinuation of oxytocin in active phase of labour- a randomised trial. J. Evolution Med. Dent. Sci. 2019;8(44):3342-3346, DOI: $10.14260 /$ jemds $/ 2019 / 725$

Submission 19-08-2019, Peer Review 29-09-2019, Acceptance 05-10-2019, Published 04-11-2019.

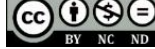




\section{BACKGROUND}

Oxytocin is a neurohypophyseal hormone that induces uterine contraction and is used for induction and augmentation of labour. Since oxytocin was first synthesized in 1953, it has become one of the most widely used medications in obstetrics. ${ }^{1,2,3}$ Although various oxytocin regimens for the induction or augmentation of labour have been described, relatively few studies have focused on the duration of oxytocin administration and its discontinuation in labour. ${ }^{4}$ Oxytocin receptor desensitization is a phenomenon that occurs after prolonged agonist stimulation and may last for hours or even days. Desensitization of oxytocin receptors may have clinical implications in terms of uterine contractility, during intrapartum and postpartum period leading to prolongation of different phases of labour, uterine hypotonia and postpartum haemorrhage. So discontinuation of oxytocin in active stage of labour may prove to be beneficial in preventing receptor desensitization which will have a reflection in terms of duration of labour as well as on events in the third stage of labour. ${ }^{5}$ Prolonged oxytocin infusion can have the following harmful effects in terms of uterine tachysystole, non-reassuring foetal heart rate pattern and consequent increased rate of caesarean section. So, discontinuation of oxytocin in established active phase of labour can avoid all these adverse outcomes.

\section{METHODS}

This prospective randomised controlled trial was conducted in the Department of Obstetrics and Gynaecology, R. G. Kar Medical College \& Hospital, West Bengal, India between 01.01.2017 to 30.06.2018. Institutional Ethical Committee clearance was obtained for initiation of study and a written informed consent was taken from all participants. The inclusion criteria were pregnant mothers of $>/=18$ years of age, primigravida, carrying single live foetus with cephalic presentation at 37- 42 weeks of gestation with cervical dilatation $</=3 \mathrm{~cm}$ with premature rupture of membranes. Exclusion criteria of our study were pregnant mothers at age $<18$ years, unable to give written informed consent, having any medical-surgical disorder, scarred uterus, foetus with congenital malformations, intrauterine foetal demise, persistent non- reassuring foetal heart rate pattern on admission, non- cephalic presentation and estimated foetal eight $>4 \mathrm{kgs}$ by ultrasound.

Pregnant mothers with premature rupture of membranes, entering the delivery unit were examined and only women with cervical dilatation $</=3 \mathrm{~cm}$ and who have not received any labour induction agent for cervical ripening were included and randomised.

After randomisation, intravenous oxytocin infusion was started according to study protocol. Vaginal examination was performed periodically to note cervical dilatation, effacement, rotation and descent of the foetal head. Progress of labour and its complications were observed by same attending doctor to reduce inter-observer variability. 200 participants were randomly assigned following simple randomisation procedure (Computerized random numbers) into 2 groups, case (Oxytocin discontinued group) and control (Oxytocin continued group). 100 patients were allocated in each group. Masking was not done.

Intravenous oxytocin (1.5 units diluted in $500 \mathrm{ml}$ of isotonic saline) was initiated at a rate of $3 \mathrm{mIU} / \mathrm{min}$ and increased every 30 minutes by $3 \mathrm{mIU} / \mathrm{min}$ until adequate uterine contraction ( 3 to 4 contractions every 10 minutes) was established. Maximum dose of infusion was set at $15 \mathrm{mIU} / \mathrm{min}$. In the discontinued (CASE) group, oxytocin infusion was discontinued when cervical dilatation of $5 \mathrm{~cm}$ was achieved and these patients were maintained on intravenous infusion of isotonic saline only. In case of arrest of labour (No cervical dilatation for 2 hours) oxytocin infusion was restarted. For continued group (Control), oxytocin infusion was continued till delivery unless complications like uterine tachysystole or foetal heart abnormalities occurred.

Labour monitoring was done by partograph and cardiotocography (Either intermittent or continuous as per need).The primary outcome measure was duration of active phase of labour, defined as the period of labour from cervical dilation of $5 \mathrm{~cm}$ to full dilatation i.e. $10 \mathrm{~cm}$. The secondary outcomes were the duration of second stage of labor, maximum and total dose of oxytocin used. Mode of delivery, uterine tachysystole i.e. $>5$ contractions in 10 minutes, foetal heart rate pattern abnormalities on cardiotocography, postpartum haemorrhage and neonatal outcomes (APGAR score at 5 minutes, perinatal asphyxia, meconium aspiration, convulsion, hypoglycemia and NICU admission).

\section{Statistical Analysis}

The data were analysed according to the intention -to-treat principle. All quantitative variables were estimated using mean and standard deviation. Means were compared by student's t-test. Qualitative (categorical) variables were estimated as frequencies and proportions and they were compared by Chi-square test. All statistical tests were performed setting the significance level of $\alpha$ (alpha) $=0.050$.

\section{RESULTS}

\begin{tabular}{|c|c|c|c|c|c|}
\hline & & OD & OC & $\begin{array}{c}\text { Chi-Square } \\
\text { Value }\end{array}$ & $\mathbf{p}$ \\
\hline Age & $\begin{array}{l}18-22 \\
23-26 \\
27-31\end{array}$ & $\begin{array}{c}63(63 \%) \\
31(31 \%) \\
6(6 \%)\end{array}$ & $\begin{array}{l}66(66 \%) \\
22(22 \%) \\
12(12 \%)\end{array}$ & 3.59 & 0.16 \\
\hline Religion & $\begin{array}{c}\text { Hindu } \\
\text { Muslim }\end{array}$ & $\begin{array}{l}46(46 \%) \\
54(54 \%)\end{array}$ & $\begin{array}{l}40(40 \%) \\
60(60 \%)\end{array}$ & 0.73 & 0.39 \\
\hline $\begin{array}{c}\text { Socio-economic } \\
\text { status }\end{array}$ & \begin{tabular}{|c|} 
Lower (iv-v) \\
Middle (ii-iii) \\
High (i)
\end{tabular} & $\begin{array}{c}67(67 \%) \\
29(29 \%) \\
4(4 \%) \\
\end{array}$ & $\begin{array}{c}74(74 \%) \\
21(21 \%) \\
5(5 \%) \\
\end{array}$ & 1.73 & 0.41 \\
\hline Residence & $\begin{array}{l}\text { Urban } \\
\text { Rural } \\
\end{array}$ & $\begin{array}{l}39(39 \%) \\
61(61 \%) \\
\end{array}$ & $\begin{array}{l}41(41 \%) \\
59(59 \%) \\
\end{array}$ & 0.08 & 0.77 \\
\hline Education & $\begin{array}{l}\text { Primary } \\
\text { Secondary } \\
\text { Bachelor }\end{array}$ & $\begin{array}{c}64(64 \%) \\
30(30 \%) \\
6(6 \%) \\
\end{array}$ & $\begin{array}{c}70(70 \%) \\
21(21 \%) \\
9(9 \%) \\
\end{array}$ & 2.45 & 0.29 \\
\hline \multicolumn{6}{|c|}{ Table 1. Demographic Characteristics } \\
\hline \multicolumn{6}{|c|}{$\begin{array}{l}\text { (OD- Oxytocin Discontinued, OC- Oxytocin Continued) } \\
\text { Results depicted in this table suggested that no statistically significant difference } \\
\text { exists between OD and OC groups based on each of these demographic parameters } \\
\text { (p value is }>0.05 \text { in all the categories) }\end{array}$} \\
\hline
\end{tabular}




\begin{tabular}{|c|c|c|c|c|}
\hline & & OD & OC & p \\
\hline Duration of active stage of labour (in hours) & $\begin{array}{l}\text { Mean } \\
\text { SD }\end{array}$ & $\begin{array}{l}2.45 \\
0.52\end{array}$ & $\begin{array}{l}2.35 \\
0.47\end{array}$ & 0.16 \\
\hline Duration of Second stage of labour (in hours) & $\begin{array}{c}\text { Mean } \\
\text { SD }\end{array}$ & $\begin{array}{l}0.96 \\
0.27\end{array}$ & $\begin{array}{l}0.89 \\
0.23 \\
\end{array}$ & 0.08 \\
\hline \multicolumn{5}{|c|}{ Table 2. Duration of Stages of Labour } \\
\hline \multicolumn{5}{|c|}{$\begin{array}{l}\text { Student's t test showed no statistically significant difference exists between the two } \\
\text { groups. This result suggests that discontinuation of oxytocin in active phase of } \\
\text { labour does not prolong the stages of labour significantly as p value is }>0.05 \text {. }\end{array}$} \\
\hline
\end{tabular}

\begin{tabular}{|c|c|c|}
\hline & OD & OC \\
\hline Caesarean section & $20(20 \%)$ & $25(25 \%)$ \\
\hline \multicolumn{1}{|c|}{ Vaginal Delivery } & $80(80 \%)$ & $75(75 \%)$ \\
\hline Instrumental Delivery (Forceps/ Ventouse) & $06(7.5 \%)$ & $11(14.6 \%)$ \\
\hline \multicolumn{2}{|c|}{ Table 3. Mode of Delivery } \\
\hline $\begin{array}{l}\text { Chi square value }=2.07, \text { p value }=0.35 \text {. This result suggests that discontinuation of } \\
\text { oxytocin in active phase of labour does not adversely affect the mode of delivery } \\
\text { pattern in a significant way. }\end{array}$ \\
\hline
\end{tabular}

\begin{tabular}{|c|c|c|c|c|}
\hline & & $\begin{array}{c}\text { Case (Oxytocin } \\
\text { Discounted) }\end{array}$ & $\begin{array}{c}\text { Control (Oxytocin } \\
\text { Contd.) }\end{array}$ & $\mathbf{p}$ \\
\hline $\begin{array}{c}\text { Rate of oxytocin } \\
\text { infusion/min (mIU/min) }\end{array}$ & $\begin{array}{l}\text { Mean } \\
\text { SD }\end{array}$ & $\begin{array}{l}5.16 \\
1.86\end{array}$ & $\begin{array}{l}5.19 \\
2.03\end{array}$ & 0.91 \\
\hline $\begin{array}{c}\text { Total amount of oxytocin } \\
\text { used (mIU) }\end{array}$ & $\begin{array}{c}\text { Mean } \\
\text { SD }\end{array}$ & $\begin{array}{c}1748.26 \\
448.20\end{array}$ & $\begin{array}{c}1951.92 \\
546.23\end{array}$ & 0.0044 \\
\hline \multicolumn{5}{|c|}{ Table 4. Amount of Oxytocin Used } \\
\hline \multicolumn{5}{|c|}{$\begin{array}{l}\text { Student's t test was done to compare the two groups. Oxytocin continued group } \\
\text { required significantly increased amount of oxytocin that can be explained by its } \\
\text { continuous administration protocol ( } p \text { value }=0.004 \text { ). However, on the basis of rate } \\
\text { of oxytocin (mIU/min) used, there was no statistically significant difference } \\
\text { between the two groups ( } \mathrm{p} \text { value }=0.91 \text { ). }\end{array}$} \\
\hline
\end{tabular}

\begin{tabular}{|c|c|c|c|}
\hline & OD & OC & $\mathbf{p}$ \\
\hline Uterine Tachysystole & $6(6 \%)$ & $15(15 \%)$ & 0.04 \\
\hline Post-partum Haemorrhage & $15(15 \%)$ & $18(18 \%)$ & 0.56 \\
\hline Non-reassuring FHR & $8(8 \%)$ & $21(21 \%)$ & 0.01 \\
\hline Meconium Aspiration & $2(2 \%)$ & $1(1 \%)$ & $>0.05$ \\
\hline APGAR score at $5 \mathrm{mint}<7$ & $2(2 \%)$ & $3(3 \%)$ & $>0.05$ \\
\hline NICU admission & $4(4 \%)$ & $3(3 \%)$ & $>0.05$ \\
\hline \multicolumn{4}{|c|}{ Table 5. Foetomaternal \& Neonatal Complications } \\
\hline \multicolumn{4}{|c|}{$\begin{array}{l}\text { Chi-square test done and p-value indicates significantly increased incidence of } \\
\text { uterine tachysystole and non-reassuring foetal heart rate pattern in oxytocin } \\
\text { continued group of patients }(\mathrm{P}<0.05) \text {. So, oxytocin discontinuation after established } \\
\text { active phase of labour is justified to avoid the occurrence of maternal complication } \\
\text { like uterine tachysystole and foetal complication like non-reassuring foetal heart } \\
\text { rate patterns. }\end{array}$} \\
\hline
\end{tabular}

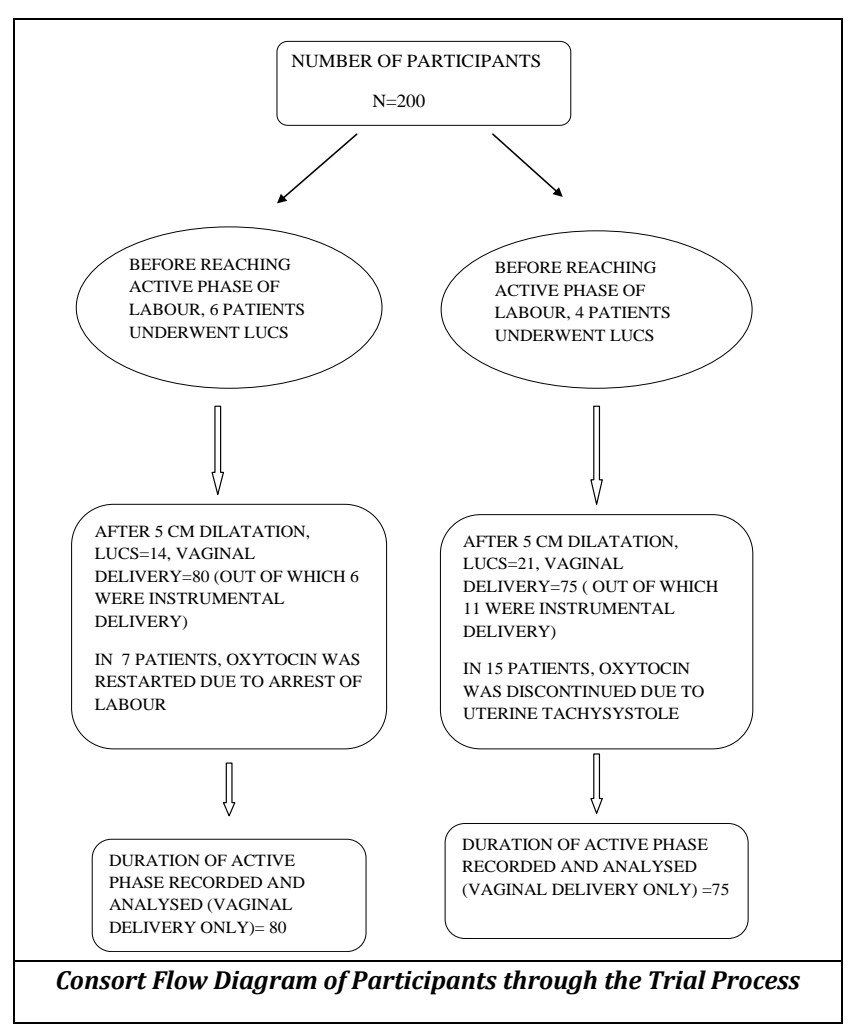

\section{DISCUSSION}

In this study the patients in whom oxytocin infusion was discontinued in the active phase of labour was taken as CASE group $(n=100)$ and where oxytocin was continued till the end of delivery of foetus was taken as CONTROL group $(n=$ 100).

\section{Demographic Characteristics}

In this study both the groups had uniform demographic characteristics. Majority of subjects were in the age group of $18-22$ years (63\% in the case group and $66 \%$ in the control group) and p value 0.16 means that there was no statistically significant difference between the two groups. Majority of the individuals were Muslims, 54\% in the case group and $60 \%$ in the control group. $\mathrm{p}$ value was 0.39 which means no statistically significant difference between two groups. Most of the patients belonged to lower socio-economic status, $67 \%$ in the case group and $74 \%$ in the control group, having no statistically significant difference $p$ value being 0.41 . Majority of population had primary level of education, $64 \%$ in the case group and $70 \%$ in the control group. p value was 0.24 which means there was no statistically significant difference.

\section{Duration of Active Stage of Labour}

- In the present study, average duration of active stage of labour in discontinued group was 2.45+/- 0.52 hours.

- $\quad$ Average duration in continued group was $2.35+/-0.47$ hours.

- $\quad$ Applying t-test, $\mathrm{p}$ value was 0.16 which means difference between the two groups was not statistically significant.

- Study by Chopra et al. ${ }^{6}$ showed that mean duration of labour after 4-6 cm cervical dilatation among oxytocin discontinued group was 6.3 hours and among oxytocin continued group was 4.7 hours (p value 0.27 ) means no statistical significance.

- Study by Ustunyurt et al. ${ }^{7}$ showed no significant difference in duration of active stage of labour among both the groups, results similar to my study.

- In contrary, study by Bor P et al. ${ }^{8}$ found the active phase of labour to be longer by 41 minutes in the discontinue group (Median 125 minutes) than in the continued group ( median 88 minutes), p value being 0.007 means significant difference.

\section{Duration of Second Stage of Labour}

- In the present study, in discontinued group it was 0.96 +/- 0.27 hours.

- Average duration in continued group was $0.89+/-0.23$ hours.

- $\mathrm{p}$ value was 0.88 , which means though the average duration of second stage of labour was little longer in oxytocin discontinued group, but the difference was not statistically significant.

- Study by Daniel-Spiegel et al showed no statistically significant difference in the duration of second stage of labour after discontinuation of oxytocin $(0.5$ hours in continued group and 0.53 hours in discontinued group). The result was similar to this study. 


\section{Total Dose and Rate of Oxytocin Usage}

In the present study, total amount of oxytocin required in the continued group was $1951.92 \mathrm{mIU}$ and in the discontinued group it was $1748.26 \mathrm{mIU}$. There was significant difference between the two groups as the p value was 0.004 . Girard et al. ${ }^{9}$ found no difference but Begum et al. ${ }^{10}$ found significant difference in total oxytocin requirement. Rate of oxytocin infusion $(\mathrm{mIU} / \mathrm{min})$ in continued group was $5.19+/-2.03$ (Mean+/- SD) and in discontinued group $5.16+/-1.86$ (Mean+/- SD). $\mathrm{p}$ value was 0.91 which means no significant difference exists. Spiegel et al and Bor et al also found no significant difference between the two groups, similar to this study.

\section{Mode of Delivery \\ Vaginal delivery occurred in $80 \%$ patients of discontinued group and $75 \%$ patients of continued group with no significant difference ( $\mathrm{p}$ value being 0.35 ). Caesarean delivery was needed in 20 patients of discontinued group (CASE) and the indications were non-reassuring foetal heart rate in the pre-active stage $(n=6)$, persistent uterine tachysystole with non-reassuring foetal heart rate $(n=4)$, arrest of descent in second stage of labour due to persistent occipito-posterior position $(n=4)$, cephalo-pelvic disproportion $(n=3)$ and features of chorio-amnionitis $(n=3) .25$ patients underwent caesarean section in continued group and the indications were non-reassuring foetal heart rate in the pre-active stage $(n=4)$, persistent uterine tachysystole with non-reassuring foetal heart rate even after stoppage of oxytocin infusion $(n=6)$, cephalo-pelvic disproportion $(n=6)$, non-progress of labour $(n=5)$ and features of chorio-amnionitis $(n=4)$. As per Chopra et al the mode of delivery was not affected by discontinuation of oxytocin similar to this study. In contrary, Spiegel et al and Utsunyurt et al found a significantly higher caesarean delivery rate in oxytocin continued group.}

\section{Maternal Complications}

Uterine tachysystole occurred in 15 patients of continued group and 6 patients of discontinued group showing significant difference $(\mathrm{P}=0.04)$ Bor et al and Begum et al got results similar to this study. 4 out of 6 patients suffering from uterine tachysystole in the oxytocin discontinued group showed abnormal foetal heart rate pattern also and had caesarean delivery. Oxytocin infusion was discontinued in 15 patients of continued group who developed uterine tachysystole in the oxytocin continued group and abnormal foetal heart rate pattern in cardiotocography. FHR improved in 9 of them who had vaginal delivery later on but 6 patients needed caesarean section for persistent foetal distress. In this study, there was no statistically significant difference in the rate of uterine atonicity and third stage haemorrhage in the two groups, so the uterine desensitization theory by continuous oxytocin stimulation was not supported by this study.

\section{Foetal Outcome}

In this study abnormal foetal heart rate pattern in CTG was significantly increased in oxytocin continued group $(p=0.01)$ as a result of increased rate of uterine tachysystole due to continuous oxytocin stimulation. Vlachos et al. ${ }^{11}$ and Heuser et al.12 had also shown that oxytocin doubled the likelihood of tachysystole with foetal heart rate changes and there is a dose- response correlation between oxytocin and tachysystole. So, discontinuation of oxytocin stimulation once active labour is established is a viable option to avoid these harmful effects. The neonatal outcome was comparable in two groups in terms of APGAR scores, meconium aspiration, and NICU admission.

Protocol Non-Compliance in Oxytocin Discontinued Group Oxytocin was restarted in seven patients, three of them were then in their first stage of labour, due to arrest of cervical dilatation for 2 hours and in four patients in the second stage of labour due to arrest of descent of the presenting part due to persistent occipito-posterior position.

\section{Protocol Non-Compliance in Oxytocin Continued Group}

In fifteen patients, oxytocin infusion was discontinued due to uterine tachysystole and consequent foetal distress. Improvement occurred in nine of them after discontinuation and they had successful vaginal delivery. Six of them needed caesarean delivery due to persistent abnormal foetal heart rate pattern even after discontinuation of oxytocin infusion.

\section{CONCLUSIONS}

Discontinuation of oxytocin in the active stage of labour does not prolong the duration of labour and has no adverse maternal or neonatal outcome. Moreover, continuation of oxytocin in active stage of labour can result in increased incidence of uterine tachysystole and foetal heart rate abnormality. Therefore, it is an alternative and viable option to discontinue oxytocin in the active stage of labour. This will not only reduce the need for intense monitoring of labour and the dangers of prolonged oxytocin use but will also reduce the cost of labour management in resource poor countries. We need further study with different dosing and duration of oxytocin administration to negate or prove the desensitization theory which assumes that continuous oxytocin administration can prolong the labour duration and can increase the chance of uterine atony and postpartum haemorrhage.

\section{ACKNOWLEDGEMENT}

We would like to thank our HOD, Department of Gynaecology and Obstetrics, honourable members of the Ethical Committee and the labour room staff for their kind cooperation.

\section{REFERENCES}

[1] Simpson KR, Knox GE. Oxytocin as a high-alert medication: implications for perinatal patient safety. MCN Am J Matern Child Nurs 2009;34(1):8-15, quiz 16-7.

[2] Selin L, Almstrom E, Wallin G, et al. Use and abuse of oxytocin for augmentation of labor. Acta Obstet Gynecol Scand 2009;88(12):1352-7. 
[3] Oscarsson ME, Amer-Wahlin I, Rydhstroem H, et al. Outcome in obstetric care related to oxytocin use. A population-based study. Acta Obstet Gynecol Scand 2006;85(9):1094-8.

[4] Merril DC, Zlatnik FJ. Randomized, double-masked comparison of oxytocin dosage in induction and augmentation of labor. J Obstet Gynecol 1999;94(3):45563.

[5] Daniel-Spiegel E, Weiner Z, Ben-Sholmo I, et al. For how long should oxytocin be continued during induction of labour? BJOG: an International Journal of Obstetrics and Gynaecology 2004;111(4):331-4.

[6] Chopra S, SenGupta SK, Jain V, et al. Stopping oxytocin in active labor rather than continuing it until delivery: a viable option for the induction of labor. Oman Medical Journal 2015;30(5):320-5.

[7] Ustunyurt E, Ugur M, Ustunyurt BO, et al. Prospective randomized study of oxytocin discontinuation after the active stage of labor is established. J Obstet Gynecol Res 2007;33(6):799-803.
[8] Bor P, Ledertoug S, Boie S, et al. Continuation versus discontinuation of oxytocin infusion during the active phase of labour: a randomized controlled trial. BJOG: an International Journal of Obstetrics and Gynaecology 2016;123(1):129-35.

[9] Girard B, Vardon D, Creveuil C, et al. Discontinuation of oxytocin in the active phase of labor. Acta Obstet Gynecol Scand 2009;88(2):172-7.

[10] Begum LN, Sutana M, Nahar S, et al. A randomized clinical trial on the need of continuing oxytocin infusion in active phase of induced labour. Chattagram Maa-0Shishu Hospital Medical College Journal 2013;12(2):2330.

[11] Vlachos DE, Pergialiotis V, Papantoniou N, et al. Oxytocin discontinuation after the active phase of labour is established. J Matern Foetal Neonatal Med 2015;28(12):1421-7.

[12] Heuser CC, Knight S, Esplin MS, et al. Tachysystole in term labour: incidence, risk factors, outcomes and effect on foetal heart tracings. Am J Obstet Gynecol 2013;209(1):32.e1-6. 